\title{
Emergence and molecular characterisation of non- toxigenic tox gene-bearing Corynebacterium diphtheriae biovar mitis in the United Kingdom, 2003-2012
}

K Zakikhany (katherina.zakikhany@folkhalsomyndigheten.se) ${ }^{1,2,3}$, S Neal $^{1}$, A Efstratiou $^{1}$

1. Public Health England, World Health Organisation Global Collaborating Centre for Diphtheria, London, United Kingdom

2. The European Programme for Public Health Microbiology Training (EUPHEM), European Centre for Disease Prevention and Control, Stockholm, Sweden

3. Current affiliation: Public Health Institute of Sweden, Stockholm, Sweden

Citation style for this article:

Zakikhany K, Neal S, Efstratiou A. Emergence and molecular characterisation of non-toxigenic tox gene-bearing Corynebacterium diphtheriae biovar mitis in the United Kingdom, 2003-2012. Euro Surveill. 2014;19(22):pii=20819. Available online: http://www.eurosurveillance.org/ViewArticle.aspx?Articleld=20819

Article submitted on 04 April 2013 / published on 05 June 2014

Non-toxigenic Corynebacterium diphtheriae have become increasingly recognised as emerging pathogens across Europe causing severe invasive disease. A subset of non-toxigenic $C$. diphtheriae are 'non-toxigenic tox gene-bearing' (NTTB) strains; these strains are genotypically toxpositive, but do not express the protein. The circulation of NTTB strains was first observed during the 1990 s upsurge of diphtheria in Eastern Europe but has not been reported in other European countries. Circulation of NTTB strains could be considered an increased risk for diphtheria and other related diseases, given their possible role as a tox gene reservoir with the theoretical risk of re-emerging toxin expression. Here we report the characterisation of 108 non-toxigenic $C$. diphtheriae biovar mitis isolates submitted to the World Health Organization (WHO) Global Reference Centre for Diphtheria at Public Health England, London, between 2003 and 2012, in order to determine the presence of NTTB strains. Using molecular methods, five NTTB isolates were identified; four human isolates (MLST type 212) and one isolate from a companion cat (MLST type 40). The emergence of these strains could indicate continuation of the circulation of potentially toxigenic strains and appropriate laboratory diagnostic methods should be used for detection. Given the complacency that currently exists in Europe awareness with regards to diphtheria diagnostics must be enhanced.

\section{Introduction}

Infections caused by toxigenic strains of Corynebacterium diphtheriae have become uncommon in Europe as a result of widespread immunisation, implemented during the first half of the $20^{\text {th }}$ Century. In the European Union (EU)/European Economic Association (EEA) countries, the number of reported (toxigenic) diphtheria cases has declined over the past years to 46, 15 and 16 confirmed cases in 2008, 2009 and 2010, respectively [1]. However, diphtheria is still present in all six World Health Orgainization (WHO) regions and new epidemics are regularly reported [2]. These and the Eastern European epidemic in the 1990s with more than 157,000 cases and 5,000 deaths between 1990 and 1998 , clearly demonstrate the unbroken threat of the disease in the post-vaccine era [3].

The toxigenicity of $C$. diphtheriae strains is solely attributed to the expression of a very potent exotoxin (DTX) which inhibits protein synthesis in mammalian cells [4]. The structural gene (tox), consisting of subunits $A$ and $B$, is carried by a corynebacteriophage and regulated by the chromosomally encoded regulator DtxR (diphtheria toxin repressor). Integration of toxcarrying bacteriophages into the bacterial genome can convert non-toxigenic strains into toxigenic and virulent strains. This transformation has been described for example in patients but is generally believed to occur rarely in nature $[4,5]$.

Typical diphtheria is caused by infection with toxigenic strains of $C$. diphtheriae, leading to respiratory or cutaneous symptoms. The characteristic of severe respiratory diphtheria is the presence of a strongly adherent greyish-white pseudomembrane, typically progressing from the tonsils into the larynx and trachea and suffocation following aspiration of the membrane is a common cause of death in untreated cases [6]. Cutaneous diphtheria is more common in tropical regions with a usually mild non-systemic clinical presentation in the form of infected skin lesions and shallow ulcers often occurring in combination with poor hygienic conditions [6]. The most effective treatment against diphtheria is the diphtheria antitoxin (DAT) which binds and neutralises circulating toxin which has not yet bound to tissue. DAT is therefore only recommended for treatment of acute disease. The only way to induce long lasting immunity and to prevent the disease is vaccination; the diphtheria vaccine is one of the oldest vaccines and available as bi- (in combination with tetanus toxoid (DT/dT)) or trivalent vaccine (tetanus, diphtheria, 
pertussis (DTacP)) or as combination vaccine with Haemophilus influenzae type b (Hib) vaccine) or inactivated polio vaccine (IPV), depending on national vaccination schedules [7].

Non-toxigenic strains have become increasingly recognised as causes of severe invasive disease causing e.g. endocarditis and bacteraemia [8-10]. Infections caused by non-toxigenic $C$. diphtheriae are not preventable by vaccination and pathogenic mechanisms are generally not well understood.

Non-toxigenic C. diphtheriae usually completely lack the tox gene; exceptionally some non-toxigenic strains also bear the tox gene. These strains are genotypically tox-positive, but do not express the protein. They are called 'non-toxigenic tox gene-bearing strains' (NTTB).

During and after the 1990 s diphtheria epidemic in countries in the Eastern part of the WHO European region, circulation of NTTB strains was widely observed. In 2004, Melnikov et al. published a study on 828 C. diphtheriae non-toxigenic strains isolated in different regions of Russia between 1994 and 2002, and found approximately $10 \%$ to be NTTB strains $[11,12]$. All NTTB strains were found to belong to $C$. diphtheriae biovar mitis; some of the isolates were from patients with severe respiratory illnesses. Molecular analyses of the NTTB isolates suggested two mechanisms contributing to the blockage of tox gene expression: a single base deletion (52-55 bp), resulting in a frame shift, or the presence of an insertion element (38-46 bp), both localised in the A-subunit of the tox gene. Similar studies have, however, not been conducted in other parts of the European region.

At present, the prevalence and epidemiological significance of $C$. diphtheriae NTTB strains across Europe is unknown. The circulation of NTTB strains could be considered an increased risk for diphtheria, given the possible role of these strains as a tox gene reservoir in the population and the theoretical possibility of re-emerging toxin expression through spontaneous reversion into toxigenic strains or through homologous recombination between different corynebacteriophages [5].

A recent and unique European screening study comprising 10 European countries and coordinated by the Diphtheria Surveillance Network (DIPNET) (13), showed that toxigenic, non-toxigenic and NTTB strains of C. diphtheriae are circulating in Europe, despite a high vaccination coverage among children in many European countries and a presumed absence of clinical disease [14]. Several European countries reported an increase in non-toxigenic $C$. diphtheriae infections in recent years based both on surveillance data and also related to outbreaks $[10,15]$.

The gold standard for laboratory diagnosis of diphtheria is the phenotypic Elek test for toxigenicity characterisation; strains that phenotypically express the toxin always carry the gene. However, if Elek is the sole test used, the presence or absence of the tox gene cannot be determined in strains not expressing toxin. The aim of this study was therefore, to determine the presence, estimate the prevalence and characterise, using molecular methods, NTTB strains submitted to the WHO Global Reference Centre for Diphtheria at Public Health England, London, United Kingdom (UK) between 2003 and 2012 in order to support public health management of diphtheria.

\section{Methods}

One-hundred and twenty-two $C$. diphtheriae biovar mitis isolates were received during the period from 15 November 2003 to 16 July 2012, all were human isolates from the UK, except for one, which was originally isolated in Belgium from a cat's nasal swab (this was referred to the reference unit for confirmation of toxigenicity). In case of multiple specimens from one individual only the first isolate was considered. All specimens received in the laboratory were cultivated on blood agar and tellurite agar for initial screening. Typing and biochemical characterisation of all isolates was performed using the API $尺$ Coryne test (API bioMérieux, Marcy l'Etoile, France) in addition to the pyrazimidase, the cystinase and the toxigenicity tests (Elek test, polymerase chain reaction (PCR)) if applicable [16]. Five isolates had been previously identified as toxigenic (tox + ) by Elek test $[17,18]$ and were excluded from the analysis together with nine specimens that could not be recultivated. PCR analysis was performed for 108 specimens. Two strains, NTTB strain 99/CD/196 (ribotype St. Petersburg, isolated in 1999) and NCTC 13129 (GenBank: NC_002935.2) were included in the molecular analysis as reference strains.

For extraction of bacterial DNA, overnight cultures of C. diphtheriae strains cultivated on blood agar were incubated at $37^{\circ} \mathrm{C}$ (16). A loopful of bacterial culture was added to $500 \mu \mathrm{l}$ sterile water and heat-treated for 30 minutes at $100^{\circ} \mathrm{C}$. Cell debris were separated by centrifugation (12,000 rpm, $1 \mathrm{~min}$ ) and the supernatant containing DNA was transferred to a sterile tube. For PCR reactions, 1-5 $\mu$ l of supernatant was used.

\section{Polymerase chain reaction and sequencing of the tox gene}

Amplification of the tox gene (subunit A) was performed as described previously $[19,20]$ using the Novocastra $C$. diphtheriae Primer Set (Leica Microsystems) according to manufacturer's instructions; each reaction included an internal positive control as amplification control. For direct DNA sequencing, the tox gene was amplified using the HotStarTaq Master Mix (Qiagen) and selected primers as previously described [21] or primers specifically designed for this study (Table 1 and Figure 1). Sequencing was performed with a BigDye Terminator v1.1 or v3.1 Cycle Sequencing kit (Applied Biosystems) and sequencing reactions were set up using the PCR primers. Sequence data were analysed using the 
TABLE 1

Primers for polymerase chain reaction analysis and sequencing of non-toxigenic tox gene-bearing Corynebacterium diphtheria, United Kingdom 2012

\begin{tabular}{|c|c|c|c|}
\hline Primer & Position $^{\mathrm{a}}$ & Nucleotide sequence $\left(5^{\prime}-3^{\prime}\right)$ & length (bp) \\
\hline Dipht 1F [21] & $(-130)-(-110)$ & TTGCTAGTGAAGCTTAGCTAG & NA \\
\hline Dipht 4R [21] & $817-837$ & TGCCGTTTGATGAAATTCTTC & 973 \\
\hline Dipht 4F [21] & 535-555 & GAACAGGCGAAAGCGTTAAGCG & NA \\
\hline Dipht 8R [21] & $1731-1751$ & TCTACCTGTGCATACTATAGC & 1217 \\
\hline NTTB $10 F^{b}$ & $(-25)-(-4)$ & ATGAGTCCTGGTAAGGGGATACGTTGT & $581^{c}$ \\
\hline NTTB $11 F^{b}$ & $(-694)-(-669)$ & AGCTGCATGAGTGTTGTAGCTGCTT & $840^{d}$ \\
\hline NTTB $12 \mathrm{~F}^{\mathrm{b}}$ & $(-399)-(-372)$ & GGCCTGATGATATTGATCTAGATGAGA & $545^{\mathrm{d}}$ \\
\hline NTTB $12 R^{b}$ & $117-146$ & TTAGTCCCGTGGTACGAAGAAAAGTTTTC & NA \\
\hline
\end{tabular}

NA: not applicable

a relative to the first nucleotide of the start codon $(+1)$

${ }^{b}$ this study

${ }^{c}$ with Dipht $4 \mathrm{R}$

${ }^{d}$ with Diph $12 R$

Nucleic acid position indicated according to Corynebacterium diphtheriae NCTC 13129 (GenBank Reference Sequence: NC_002935.2)

softwares BioNumerics (Applied Maths) and BioEdit (http://www.mbio.ncsu.edu/BioEdit/page2.html).

Multilocus sequence typing (MLST) based on a sequencing scheme comprising seven housekeeping genes was performed as described previously [22].

All isolates were subjected to both the conventional and the modified Elek tests as described previously [16-18].

\section{Antimicrobial sensitivity testing}

Antimicrobial sensitivity testing of NTTB isolates was performed according to British Society for Antimicrobial Chemotherapy (BSAC) [23]/The European Committee on Antimicrobial Susceptibility Testing (EUCAST) 2013 guidelines for coryneform organisms [24]. Using Etest strips (bioMérieux, Marcy l'Etoile, France) minimum inhibitory concentration (MIC) breakpoints in $\mathrm{mg} / \mathrm{L}$ of
$>0.12$ (resistant (R)) and 0.12 (sensible (S)) were considered for Penicillin [25].

\section{Results}

Pure cultures for the 108 C. diphtheriae biovar mitis strains were mainly referred from throat swabs $(n=87$; $80.6 \%)$, wound swabs $(n=10 ; 9.3 \%)$ and furthermore from blood culture $(n=1)$, nasal swab $(n=2)$ swab/other $(n=1)$, pus $(n=1)$, skin $(n=2)$, ulcer $(n=1)$, for three specimens, no information was provided; 62 specimens were from men (57.4\%) and one from an animal (cat). The average age of the human patients was 27.3 years (range 1-72).

C. diphtheriae biovar mitis isolates analysed in this study were submitted between July 2003 and November 2012 with the highest number of isolates submitted (per calendar year) in $2005(n=14)$ and $2004(n=10)$ and

\section{FIGURE 1}

Scheme of the tox gene and location of sequencing primers used in this study

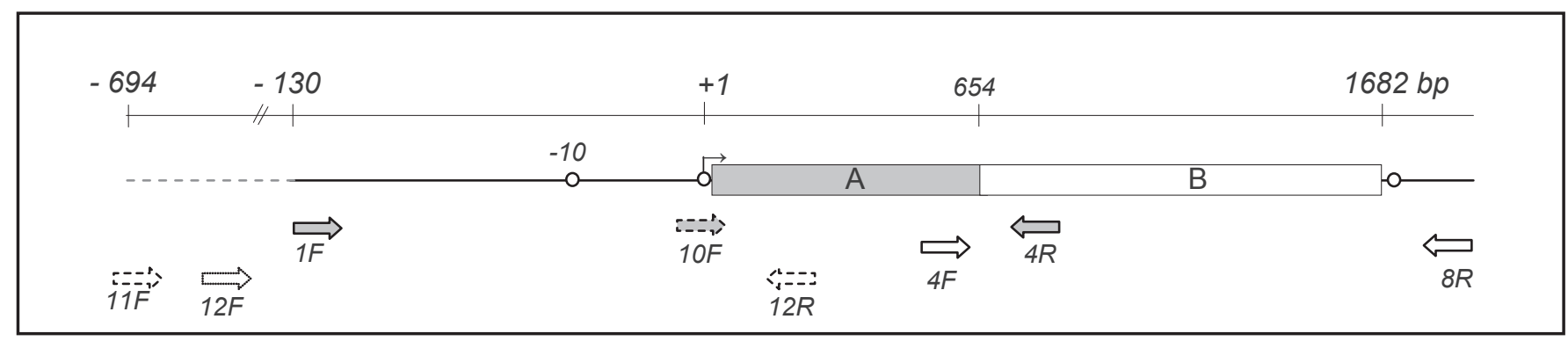

Primers were selected for sequencing of subunit A (grey) and subunit B (white) of the tox gene.Primers indicated in dotted lines were designed for sequencing and determination of the promoter and upstream region of the four human non-toxigenic tox gene-bearing Corynebacterium diphtheria isolates.

Position numbers correspond to Corynebacterium diphtheriae NCTC 13129 (GenBank Reference Sequence: NC_002935.2) 
TABLE 2

Identified non-toxigenic tox gene-bearing and toxigenic Corynebacterium diphtheriae biovar mitis strains among isolates submitted to the Diphtheria Reference Unit, United Kingdom, 2003-2012 (n=10)

\begin{tabular}{|c|c|c|c|c|}
\hline Isolate & Sex & $\mathrm{Age}^{\mathrm{a}}$ & Specimen & Characteristics \\
\hline $2011 / 1$ & $M$ & 27 & Throat swab & NTTB (PCR+, tox-) \\
\hline $2011 / 2$ & $M$ & 24 & Throat swab & NTTB (PCR+, tox-) \\
\hline $2011 / 3$ & $M$ & 24 & Throat swab & NTTB (PCR+, tox-) \\
\hline $2012 / 1$ & $M$ & 27 & Throat swab & NTTB (PCR+, tox-) \\
\hline $2012 /$ cat & \multicolumn{2}{|c|}{ Cat } & Nasal swab & NTTB (PCR+, tox-) \\
\hline $2012 / 1$ & $M$ & 67 & Wound swab & Toxigenic (PCR+, tox+) \\
\hline $2010 / 1$ & $\mathrm{~F}$ & 57 & Skin swab & Toxigenic (PCR+, tox+) \\
\hline $2009 / 1$ & $M$ & 72 & Wound swab & Toxigenic (PCR+, tox+) \\
\hline $2008 / 1$ & $M$ & 17 & Throat swab & Toxigenic (PCR+, tox+) \\
\hline $2008 / 2$ & $\mathrm{~F}$ & 7 & Bronchoalveolar lavage & Toxigenic (PCR+, tox+) \\
\hline
\end{tabular}

F: female; M: male; NTTB: non-toxigenic tox gene-bearing; PCR: polymerase chain reaction; PCR+: positive; tox: result from conventional and modified tox+/tox-: tox-positive/tox-negative in conventional and modified Elek test.

a Age refers to age at time point when specimen was taken.

Toxigenicity was determined for all strains using the conventional and modified Elek test and molecular methods (PCR).

Full antibiotic sensitivity to penicillin was determined for all non-toxigenic tox gene-bearing isolates.

a consistent number of isolates submitted between 2006 and 2011 ( $n=5$ to 8 isolates per year).

Overall, five $C$. diphtheriae biovar mitis NTTB strains (4.6\%) were identified through PCR analysis and the phenotypic non-toxigenicity for all five NTTB strains was subsequently reconfirmed, using the conventional and modified Elek tests. All five $C$. diphtheriae biovar mitis NTTB strains were referred between 2011 and 2012. One of the NTTB strains originated from a nasal swab of a cat. All four human strains were isolated from throat swabs taken from men (Table 2).

Molecular characterisation of tox gene-bearingand toxigenic Corynebacterium diphtheriae

biovar mitis strains

The five identified $C$. diphtheriae biovar mitis NTTB isolates were subjected to further molecular analysis which included whole tox gene sequencing (Figure 2) and molecular typing using MLST [22]. For control and reference purposes, three of the toxigenic strains ( $C$. diphtheriae biovar mitis, 2010/1, 2008/1 and 2008/2 (Table 1)) and one previously described NTTB strain from the 1990 E Eastern European diphtheria epidemic (St. Petersburg 1999/196) were also included.

Analysis of the sequencing data revealed the presence of the whole tox gene, including subunits $A$ and $B$ for all five NTTB isolates. In contrast, the NTTB strain St. Petersburg 1999/196 contained only subunit A of the tox gene. Subsequent sequence analysis revealed identical sequences for all isolates subjected to sequencing for the tox subunit $B$ (data not shown) and sequence variations for toxsubunit $A$ and within the respective promoter regions (Figure 2).
All four human NTTB strains showed identical sequences for the tox subunit $A$ which included a one base pair (bp) deletion at position 25 (Figure 2). The region upstream from the start codon could not be sequenced in the four human NTTB isolates, which included the promoter region, approximately $690 \mathrm{bp}$, from position -25 to -694 , strains $2011 / 1-3,2012 / 1$ (Figure 2).

Interestingly, tox subunit A in the animal NTTB isolate (2012/cat) was identical to the Russian NTTB strain (St. Petersburg 1999/196) and included an identical promoter region, a one base pair deletion (bp 55) and a one base pair substitution (bp 60) in comparison to the toxigenic strains (Figure 2).

Molecular typing, using MLST, revealed similar MLST sequence types (ST) for the four human NTTB strains (ST 212) and different MLST sequence types for the NTTB isolate from the cat (ST 40) and the toxigenic isolates (STs 500 and 67).

\section{Basic epidemiological features}

Only basic epidemiological information for the NTTB isolates could be extracted from the laboratory referral forms. All four human NTTB isolates were throat swabs and collected from young men (Table 1) temporally and/or spatially dispersed. Specimens 2011/1 and 2011/2 were both collected during the same week in April 2011 but in different cities in the UK (distance > $300 \mathrm{~km}$ ). Isolate 2011/3 was collected November 2011 and in the same city as isolate $2011 / 2$. Subsequently, isolate 2012/1 was collected in January 2012 in the same city as isolate 2011/1. No clinical or further epidemiological information was provided on the referral 
tox gene sequence alignment $(-75-+62 \mathrm{bp})$ of non-toxigenic tox gene-bearing Corynebacterium diphtheriae biovar mitis strains identified and selected reference strains, United Kingdom 2012

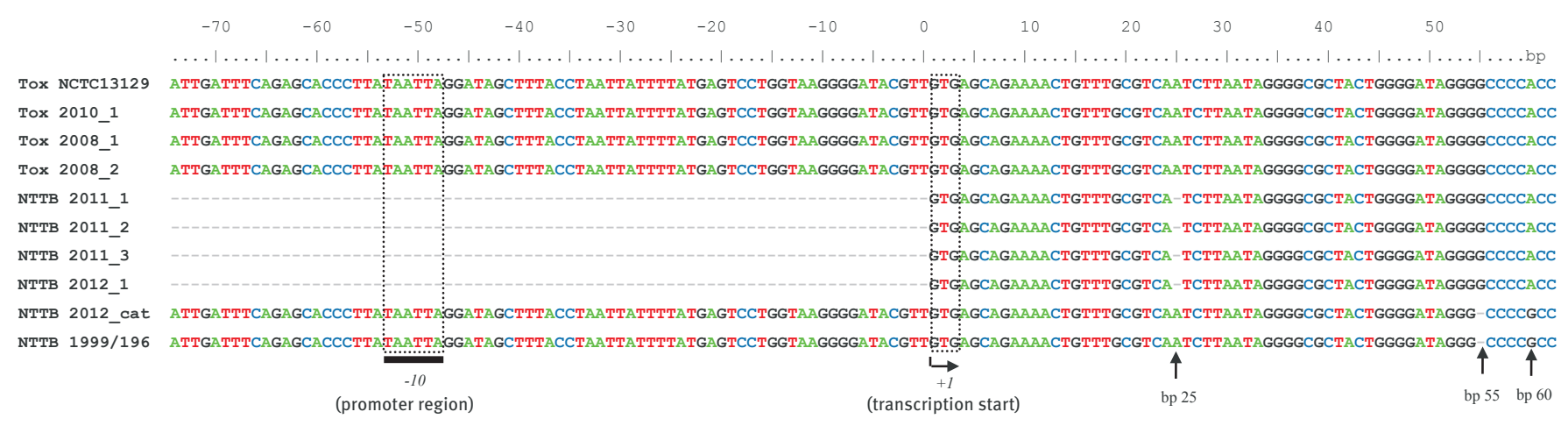

NTTB: non-toxigenic tox gene-bearing; Tox: toxigenic strains.

Sequencing analysis revealed identical sequences for the four human isolates (NTTB 2011/1-3, 2012/1) including a one base pair deletion (bp 25) and a C>T replacement (bp 244, data not shown). Sequence similarity was revealed for the animal NTTB isolate (NTTB 2012/cat) and the reference Russian isolates (NTTB 199/196) including a one base pair deletion (bp 55) and base pair replacements (bp 60 (A>G) and 431 (G>A, not shown)). All deletions and replacements were located within subunit-A of the tox gene.

forms. The animal isolate was from a nasal swab taken from a cat whose owner was diagnosed with a C. ulcerans leg ulcer infection.

\section{Discussion}

Non-toxigenic $C$. diphtheriae are increasingly recognised as pathogens across Europe (26). However, in contrast to the toxigenic $C$. diphtheriae strains, disease and epidemiology is less well understood and monitored and currently, non-toxigenic $C$. diphtheriae are not included in the case-definitions for surveillance of diphtheria in Europe [27] and no public health action beyond antibiotic treatment is implemented [28].

In the 1990 s and during the upsurge of epidemic diphtheria in Eastern Europe, a subset of non-toxigenic C. diphtheriae were described which were tox genepositive, but did not express the protein, the so called NTTB. In this study, we describe, to our knowledge, for the first time after the epidemic upsurge of diphtheria in the 1990s, systematic screening for NTTB strains, conducted among non-toxigenic $C$. diphtheriae biovar mitis isolates submitted from the UK (plus one animal isolate from Belgium) to the WHO Global Reference Centre at Public Health England, between 2003 and 2012. Overall, five NTTB isolates ( $4.6 \%)$ were identified among 108 specimens, isolated from four human patients and one animal (cat) carrier. Unfortunately, no information could be obtained on the nature of symptoms or the severity of disease amongst the patients.

MLST of the four human NTTB isolates revealed sequence type (ST) 212 for all four isolates. This ST has until now only been documented twice in the published literature $(29,30)$. Interestingly, both reports described men; one symptomatically infected with a toxigenic $C$. diphtheriae biovar mitis (ST 212) strain and one asymptomatic carrier of $C$. diphtheriae biovar mitis (ST 212), retrospectively identified as an NTTB strain [29,30]. Furthermore, all six ST 212 C. diphtheriae biovar mitis isolates described thus far were collected between March 2011 and January 2012; however, they were widely dispersed across Europe (France, Germany, UK).

This study shows that $C$. diphtheriae biovar mitis NTTB strains are circulating in the UK. The temporal pattern, the limited information about patients and the basic molecular analysis of the four human isolates suggests a recent clonal introduction and spread rather than a wide circulation of NTTB strains in the UK. Sequence type 212 described in the German case report (30) was associated with sexual transmission and interestingly, all six ST 212 isolates described to date were isolated from men. Sexually transmitted or -associated diphtheria infections have been described rarely in the literature thus far. A prospective screening study from the 1990 s performed at a Genitourinary Medicine (GUM) Clinic in the UK found six (1\%) mildly symptomatic pharyngeal carriers of $C$. diphtheriae in a cohort of 578 homosexual men and one (0.05\%) asymptomatic carrier in a cohort of 653 heterosexual men and no carriers among 1,043 women [31], but similar and more recent studies are lacking. However, a more detailed and discriminatory molecular analysis (e.g. ribotyping) in addition to detailed epidemiological information is required to allow definite conclusions about the route of transmission.

Molecular analysis of the four human NTTB isolates revealed a new genetic pattern, including a potential deletion of approximately 600 bp's upstream of the start codon which could not be sequenced and a one 
base pair deletion at position 25 within tox subunit $A$ . Previously and during the 1990 s diphtheria epidemic characterised NTTB strains were described with a single base pair deletion (bp 52-55) or the presence of an insertion element (bp 38-46) [11,12]. Despite various attempts using PCR-based methods, the nature of genetic rearrangements in the promoter region of the four human NTTB isolates could not be determined. Further studies including e.g. whole-genome sequencing are needed to analyse the genetic rearrangements and understand the phylogenetic evolution of these strains. Ideally this study could be aimed at a more comprehensive strain collection of NTTB strains circulating in different countries in Europe and beyond.

Interestingly, sequencing analysis of subunit $\mathrm{A}$ of the tox gene of the animal NTTB isolate (2012/cat) revealed identical sequences with the Russian NTTB isolate (1999/96), representing the 'old' NTTB strains circulating during the 1990 Eastern European epidemic. Thus far, only one similar case has been reported in the literature; in 2010 a non-toxigenic $C$. diphtheriae, biovar belfanti though, was isolated from a domestic cat and retrospectively identified as an NTTB strain [32].

In a recent study on 103 non-toxigenic C. diphtheriae isolates collected between 1977 and 2011 in France, the authors described an increasing resistance to selected antibiotics and the potential risk of non-toxigenic strains expressing the diphtheria toxin after being lysogenised by a corynephage harbouring the tox gene [33]. However, the role and function of NTTB strains within this context and from a public health point of view has yet to be determined. Firstly, the emergence of these potentially 'toxigenic' strains indicates a potential reservoir for tox sequences among circulating strains in the population, which, together with effects of waning immunity [34] and decreasing laboratory capacity for detection of diphtheria in many countries, poses an increased risk for disease and outbreaks. Secondly, the public health management of these patients is unclear; no general guidelines are available on the evaluation of cases and contacts including therapeutic measures such as antibiotic eradication therapy.

Here we report that $C$. diphtheriae NTTB strains are circulating in the UK, associated with a very distinct molecular pattern among the four human isolates, and interestingly, also associated with animal carriage (cat). The presence of $C$. diphtheriae NTTB strains has also been reported from other European countries but only associated with individual cases and systematic data are not available.

Our data together with data from other European countries provides evidence that non-toxigenic, toxigenic and NTTB strains of $C$. diphtheriae are still circulating in Europe. The occurrence of diphtheria has always been characterised by periodicity and epidemic waves and while disease caused by toxigenic strains of $C$. diphtheriae has become rare in the majority of countries in the WHO European region, non-toxigenic strains of $C$. diphtheriae have been increasingly recognised as emerging pathogens in several European countries. This together with a changing epidemiological pattern (e.g. shift in the age of patients) [35], the detection of multidrug-resistant (MDR) strains [36], reports of zoonotic transmission of $C$. ulcerans [37] and the global circulation of toxigenic strains [2,38], demonstrates the continuous threat posed by this ancient disease.

Complacency that currently exists in Europe with regards to diphtheria circulation and diagnostics should be addressed through regular snapshot or screening studies across European countries, together with both laboratory and epidemiological vigilance and the maintenance of high vaccination coverage. Our study also highlights the importance of close collaboration between clinicians, public health experts and microbiologists to ensure timely data exchange and information flow as our study was hampered in parts by the unavailability of supporting clinical data. Complex public health situations, such as diphtheria management require multidisciplinary approaches and rely on effective communication both on national and international levels.

\section{Acknowledgments}

All members of the WHO Global Reference Centre for Diphtheria at Public Health England, London, United Kingdom, especially Ginder Mann for technical support.

\section{Conflict of interest}

None declared.

Authors' contributions

Conceived the project: $\mathrm{AE}, \mathrm{SN}$, performed the experiments: $K Z$, analysed the data: KZ, SN, wrote the paper: KZ, contributed to paper writing/editing: $\mathrm{AE}, \mathrm{SN}$.

References

1. European Centre for Disease Prevention and Control (ECDC). Annual epidemiological report 2012. Reporting on 2010 surveillance data and 2011 epidemic intelligence data Stockholm: ECDC; 2013. Available from: http://www. ecdc.europa.eu/en/publications/Publications/AnnualEpidemiological-Report-2012.pdf.

2. World Health Organization (WHO). Diphtheria reported cases. Geneva: WHO. [Accessed 1 Jun 2014]. Available from: http:// apps.who.int/immunization_monitoring/globalsummary/ timeseries/tsincidencediphtheria.html

3. Dittmann S, Wharton M, Vitek C, Ciotti M, Galazka A, Guichard $\mathrm{S}$, et al. Successful control of epidemic diphtheria in the states of the Former Union of Soviet Socialist Republics: lessons learned. J Infect Dis. 2000;181 Suppl 1:S10-22. http://dx.doi. org/10.1086/315534

4. Holmes RK. Biology and molecular epidemiology of diphtheria toxin and the tox gene. J InfectDis. 2000;181 Suppl 1:S156-67.

http://dx.doi.org/10.1086/315554 
5. Pappenheimer AM, Jr., Murphy JR. Studies on the molecular epidemiology of diphtheria. Lancet. 1983;2(8356):923-6. http://dx.doi.org/10.1016/S0140-6736(83)90449-X

6. Murphy JR. Corynebacterium Diphtheriae. In: Baron S, editor. Medical Microbiology. 4th ed. Galveston (TX): University of Texas Medical Branch at Galveston; 1996.

7. European surveillance network for vaccine-preventable diseases (EUVAC.NET). National Childhood Vaccination Schedules. EUVAC.NET. [Accessed 1 Jun 2014] Available from: http://www.euvac.net/graphics/euvac/vaccination/ vaccination html

8. Kanungo R, Vijayalakshmi N, Nalini P, Bhattacharya S. Diphtheria due to non-toxigenic Corynebacterium diphtheriae: a report of two cases. Indian J Med Microbiol. 2002;20(1):50-2.

9. Reacher M, Ramsay M, White J, De Zoysa A, Efstratiou A, Mann G, et al. Nontoxigenic corynebacterium diphtheriae: an emerging pathogen in England and Wales? Emerg Infect Dis. 2000;6(6):640-5.

10. Zasada AA, Baczewska-Rej M, Wardak S. An increase in nontoxigenic Corynebacterium diphtheriae infections in Poland- molecular epidemiology and antimicrobial susceptibility of strains isolated from past outbreaks and those currently circulating in Poland. Int J Infect Dis. 2010;14(10): e907-12. http://dx.doi.org/10.1016/j.ijid.2010.05.013

11. Mel'nikov VG, Kombarova Slu, Borisova Olu, Volozhantsev NV, Verevkin VV, Volkovoi KI, et al. [Corynebacterium diphtheriae nontoxigenic strain carrying the gene of diphtheria toxin]. Zh Mikrobiol Epidemiol Immunobiol. 2004(1):3-7. Russian.

12. Melnikov VG, Dezoysa A, Mazurova I, Kombarova SI, Borisova OI, Engler K, et al. Molecular screening for the "identification" of non-toxigenic tox bearing strains of Corynebacterium diphtheriae from the Russian Federation. Proceedings of the Sixth International Meeting of the European Laboratory Working Group on Diphtheria, Brussels, Belgium, June 2000. Brussels: 2000. p. 60.

13. European Commission. Europa - Public Health - Programme Funded p. DIPNET - European Diphtheria Surveillance Network [Accessed 1 Jun 2014]. 2005. http://www.eurosurveillance.org/ ViewArticle.aspx?Articleld $=754$

14. Wagner KS, White JM, Neal S, Crowcroft NS, Kupreviciene N, Paberza R, et al. Screening for Corynebacterium diphtheriae and Corynebacterium ulcerans in patients with upper respiratory tract infections 2007-2008: a multicentre European study. Clin Microbiol Infect. 2011;17(4):519-25. http://dx.doi. org/10.1111/j.1469-0691.2010.03269.X

15. von Hunolstein C, Alfarone G, Scopetti F, Pataracchia $M$, La Valle R, Franchi F, et al. Molecular epidemiology and characteristics of Corynebacterium diphtheriae and Corynebacterium ulcerans strains isolated in Italy during the 1990s. J Med Microbiol. 2003;52(Pt 2):181-8. http://dx.doi. org/10.1099/jmm.0.04864-0

16. Efstratiou A, Engler KH, Mazurova IK, Glushkevich T, VuopioVarkila J, Popovic T. Current approaches to the laboratory diagnosis of diphtheria. J Infect Dis. 2000;181 Suppl 1:S138-45. http://dx.doi.org/10.1086/315552

17. Elek D. The plate virulence test for diphtheria. J Clin Pathol. 1949;2(4):250-8. http://dx.doi.org/10.1136/jcp.2.4.250

18. Engler KH, Glushkevich T, Mazurova IK, George RC, Efstratiou A. A modified Elek test for detection of toxigenic corynebacteria in the diagnostic laboratory. J Clin Microbiol. 1997;35(2):495-8.

19. Pallen MJ. Rapid screening for toxigenic Corynebacterium diphtheriae by the polymerase chain reaction. J Clin Pathol. 1991;44(12):1025-6. http://dx.doi.org/10.1136/jcp.44.12.1025

20. Pallen MJ, Hay AJ, Puckey LH, Efstratiou A. Polymerase chain reaction for screening clinical isolates of corynebacteria for the production of diphtheria toxin. J Clin Pathol. 1994;47(4):353-6. http://dx.doi.org/10.1136/jcp.47.4.353

21. Nakao H, Pruckler JM, Mazurova IK, Narvskaia OV, Glushkevich T, Marijevski VF, et al. Heterogeneity of diphtheria toxin gene, tox, and its regulatory element, $\mathrm{dtx}$, in Corynebacterium diphtheriae strains causing epidemic diphtheria in Russia and Ukraine. J Clin Microbiol. 1996;34(7):1711-6.

22. Bolt F, Cassiday P, Tondella ML, Dezoysa A, Efstratiou A, Sing $A$, et al. Multilocus sequence typing identifies evidence for recombination and two distinct lineages of Corynebacterium diphtheriae. J Clin Microbiol. 2010;48(11):4177-85. http:// dx.doi.org/10.1128/JCM.00274-10

23. Susceptibility Testing. The British Society for Antimicrobial Chemotherapy BSAC- 2013. [Accessed 1 Jun 2014]. Available from: http://bsac.org.uk/susceptibility/

24. The European Committee on Antimicrobial Susceptibility Testing (EUCAST). Clinical breakpoints for antimicrobial susceptibility testing. EUCAST. [Accessed 1 Jun 2014 ]. Available from: http://www.eucast.org/clinical_breakpoints/
25. Howe RA, Andrews JM, BSAC Working Party on Susceptibility Testing. BSAC standardized disc susceptibility testing method (version 11). J Antimicrob Chemother. 2012;67(12):2783-4. http://dx.doi.org/10.1093/jac/dks391

26. Funke G, Altwegg M, Frommelt L, von Graevenitz A. Emergence of related nontoxigenic Corynebacterium diphtheriae biotype mitis strains in Western Europe. Emerg Infect Dis. 1999;5(3):477-80. http://dx.doi.org/10.3201/eid0503.990326

27. The Commision of the European Communities: Case definitions for reporting communicable diseases to the Community network 2008. Available from: http://ec.europa. eu/health/communicable_diseases/early_warning/ comm_legislation_en.htm

28. Public Health England (PHE). Public health control and management of diphtheria (in England and Wales). Interim Guidelines (Diphtheria Guidelines Working Group). London: 2014. Available from: http://www.hpa.org.uk/webc/ HPAwebFile/HPAweb_C/1317141014343.

29. Rousseau C, Belchior E, Broche B, Badell E, Guiso N, Laharie I, et al. Diphtheria in the south of France, March 2011. Euro Surveill. 2011;16(19): $\mathrm{pii}=19867$.

30. Berger A, Lensing C, Konrad R, Huber I, Hogardt M, Sing A. Sexually transmitted diphtheria. Sex Transm Infect. 2013;89(2):100-1. http://dx.doi.org/10.1136/sextrans-2011-050418

31. Wilson AP. The return of Corynebacterium diphtheriae: the rise of non-toxigenic strains. I Hosp Infect. 1995;30 Suppl:306-12. http://dx.doi.org/10.1016/0195-6701(95)90033-0

32. Hall AJ, Cassiday PK, Bernard KA, Bolt F, Steigerwalt AG, Bixler D, et al. Novel Corynebacterium diphtheriae in domestic cats. Emerg Infect Dis. 2010;16(4):688-91. http://dx.doi. org/10.3201/eid1604.091107

33. Farfour E, Badell E, Dinu S, Guillot S, Guiso N. Microbiological changes and diversity in autochthonous non-toxigenic Corynebacterium diphtheriae isolated in France. Clin Microbiol Infect. 2013;19(10):980-7. http://dx.doi. org/10.1111/1469-0691.12103

34. Edmunds WJ, Pebody RG, Aggerback H, Baron S, Berbers G, Conyn-van Spaendonck MA, et al. The sero-epidemiology of diphtheria in Western Europe. ESEN Project. European SeroEpidemiology Network. Epidemiol Infect. 2000;125(1):113-25. http://dx.doi.org/10.1017/S0950268899004161

35. Galazka A. The changing epidemiology of diphtheria in the vaccine era. J Infect Dis. 2000;181 Suppl 1:S2-9. http://dx.doi. org/10.1086/315533

36. Mina NV, Burdz T, Wiebe D, Rai JS, Rahim T, Shing F, et al. Canada's First Case of a Multidrug-Resistant Corynebacterium diphtheriae Strain, Isolated from a Skin Abscess. J Clin Microbiol. 2011;49(11):4003-5. http://dx.doi.org/10.1128/ JCM.05296-11

37. Dixon B. Dangerous horseplay. Lancet Infect Dis. 2010;10(11):741. http://dx.doi.org/10.1016/ S1473-3099(10)70230-9

38. World Health Organization (WHO). Immunization, Vaccines and Biologicals: WHO recommendations for routine immunization 2012. Geneva: WHO. Avaliable from: http://www.who.int/ immunization/policy/immunization_tables/en/ 
